\title{
Inflammasome Activation by ATP Enhances Citrobacter rodentium Clearance through ROS Generation
}

\author{
Michael Bording-Jorgensen ${ }^{\mathrm{a}, \mathrm{b}}$ Misagh Alipour ${ }^{\mathrm{b}, \mathrm{c}} \quad$ Ghazal Danesh $^{\mathrm{b}, \mathrm{c}}$ Eytan Wine $\mathrm{E}^{\mathrm{a}, \mathrm{b}, \mathrm{c}}$ \\ aDepartment of Physiology, ${ }^{b}$ Center of Excellence for Gastrointestinal Inflammation and Immunity \\ Research, 'Department of Pediatrics, University of Alberta, Edmonton, Alberta, Canada
}

\section{Key Words}

IL-1 $•$ NLRP3 • Bacterial clearance • Macrophages $•$ J774A.1 cells

\begin{abstract}
Background: Nod-like receptor family, pyrin domain containing 3 (NLRP3) is an important cytosolic sensor of cellular stress and infection. Once activated, NLRP3 forms a multiprotein complex (inflammasome) that triggers the maturation and secretion of interleukin (IL)- $1 \beta$ and IL-18. We aimed to define the consequences of NLRP3 induction, utilizing exogenous adenosine triphosphate (ATP) as an inflammasome activator, to determine if inflammasome activation increases macrophage killing of Citrobacter rodentium and define mechanisms. Methods: Bacterial survival was measured using a gentamicin protection assay. Inflammasome activation or inhibition in mouse J774A.1 macrophages were assessed by measuring IL-1 $\beta$; cytokines and reactive oxygen species (ROS) were measured by ELISA and DCFDA, respectively. Results: Activation of the inflammasome increased bacterial killing by macrophages and its inhibition attenuated this effect with no impact on phagocytosis or cell death. Furthermore, inflammasome activation suppressed pro-inflammatory cytokines during infection, possibly due to more effective bacterial killing. While the infection increased ROS production, this effect was reduced by inflammasome inhibitors, indicating that ROS is inflammasomedependent. ROS inhibitors increased bacterial survival in the presence of ATP, suggesting that inflammasome-induced bacterial killing is mediated, at least in part, by ROS activity. Conclusion: Improving inflammasome activity during infection may increase bacterial clearance by macrophages and reduce subsequent microbe-induced inflammation.
\end{abstract}

\section{Introduction}

The Nod-like receptor family, pyrin domain containing 3 (NLRP3) protein is a cytosolic sensor of danger-associated molecular patterns (DAMPs) and microbe-associated molecular patterns (MAMPs) [1]. When activated, the multiprotein complex NLRP3 inflammasome is formed, leading to the maturation and release of the pro-inflammatory cytokines interleukin (IL)-1 $\beta$ and IL-18 [2]. Inflammasome activation requires two signals, the first being 


\section{Cellular Physiology \\ \begin{tabular}{ll|l} 
and Biochemistry Published onIIne: January 18, 2017 & $\begin{array}{l}\text { (c) } 2017 \text { The Author(s). Published by S. Karger AG, Basel } \\
\text { www.karger.com/cpb }\end{array}$ \\
\hline Bording-Jorgensen et al. Inflammasome Enhances Bacterial Clearance by Macrophages
\end{tabular}}

production of pro-IL-1 $\beta / \mathrm{IL}-18$ and the second involves autocleavage of pro-caspase- 1 when the inflammasome assembles. Mature caspase- 1 then cleaves pro-IL-1 $\beta$ into the active form, which is subsequently secreted from the cell [2-4]. Inflammasomes and IL-1 $\beta$ have been linked to a variety of chronic immune-mediated disorders, such as gout and rheumatoid arthritis, where increased inflammasome activity appears to be detrimental [5]. In contrast, there is significant evidence that inflammasomes play an opposite role in inflammatory bowel diseases (IBD, including Crohn disease and ulcerative colitis) [6-10]. Individuals with Crohn disease have been shown to have lower expression of IL-1 $\beta$ and the NLRP3 gene, suggesting a protective role for the inflammasome, which we speculate may be explained by more effective control of invasive microbes [11].

Adenosine triphosphate (ATP), a DAMP with low extracellular levels under homeostatic conditions, can be released by damaged cells, secreted by neutrophils, or directly from intestinal bacteria during infection or necrosis, eliciting an immune response [12]. The extracellular ATP sensor purinergic receptor $\mathrm{P}_{2} \mathrm{X}_{7}$ has been proposed to activate the NLRP3 inflammasome through reactive oxygen species (ROS) production and potassium ( $\mathrm{K}^{+}$) efflux, although the precise mechanism of activation is not known [13-15]. The inflammasome is important during bacterial infection and ATP can have a protective role through promoting the production of ROS, which then eliminates bacteria $[16,17]$. P2X $\mathrm{X}_{7}$ recruits pannexin 1 , which forms a pore in the cell membrane, allowing for efflux of $\mathrm{K}^{+}$, another activator of the NLRP3 inflammasome [18]. The ROS scavenger $N$-acetylcysteine (NAC) and the NADPH oxidase ROS inhibitors diphenyleneiodonium (DPI) and apocynin (all of which will be referred to as ROS inhibitors) result in decreased NLRP3 expression and activation in murine macrophages [3]. Xiang et al. showed that ATP offered protection from peritonitis in mice infected with Staphylococcus aureus and Escherichia coli [12]. Csoka et al. demonstrated the ability of macrophages to increase intracellular killing of $E$. coli through purinergic receptors during sepsis, highlighting the beneficial effects of ATP through the inflammasome in an in vivo model [19].

Citrobacter rodentium is a mouse pathogen that colonizes the colon and causes IBDlike colitis and is used as a model for enterohemorrhagic E. coli and enteropathogenic E. coli infections. In our previous work, we showed that extraneous IL-1 $\beta$ improves the ability of macrophages to phagocytose $\mathrm{C}$. rodentium in Nlrp3\% mice and that clearance of infection is dependent on the NLRP3 inflammasome [20]. As an extension of these findings, we aimed to optimize bacterial handling and hypothesized that increasing inflammasome activation would also improve the ability of macrophages to kill these pathogens. In this study we examined the role of ATP-induced inflammasome activation in the murine macrophage cell line J774A.1 in clearing C. rodentium infection. We found that inflammasome activation decreased intracellular microbial survival along with a decrease in pro-inflammatory cytokines after the clearance of the pathogen. In addition, inflammasome activation induced ROS production, which was the cause of decreased bacterial survival. This study illustrates that the protective role of ATP-induced inflammasome activation in J774A.1 macrophages is mediated by ROS production through inflammasome activation and that optimization of inflammasome function could reduce inflammation.

\section{Materials and Methods}

Chemicals

2, 7-dichlorofluorescein diacetate (DCFDA, D6883), N-acetylcysteine (NAC, A7250), diphenyleneiodonium (DPI, D2926), apocynin (W508454), and Amicon Ultra-4 centrifugal filters (Z648035) were purchased from Sigma Aldrich. ATP (BP413-25) was purchased from Acros Organics.

Cell culture

J774A.1 murine macrophage cell line (ATCC, TIB-67) was seeded into either 24- or 96-well plates as indicated for each experiment. Cells were maintained in DMEM, supplemented with $10 \%$ heat-inactivated 


\section{Cellular Physiology Cell Physiol Biochem 2017;41:193-204 \\ \begin{tabular}{ll|l} 
and Biochemistry & $\begin{array}{l}\text { DOI: 10.1159/000455988 } \\
\text { Published onlIne: January 18, } 2017\end{array}$ & $\begin{array}{l}\text { (c) } 2017 \text { The Author(s). Published by S. Karger AG, Basel } \\
\text { www.karger.com/cpb }\end{array}$ \\
\hline Bording-Jorgensen et al. Inflammasome Enhances Bacterial
\end{tabular}}

fetal bovine serum; medium was replaced every two days and cells were passaged at $80 \%$ confluence for a maximum of 22 passages.

\section{C. rodentium infection}

J774A.1 cells were seeded in 24-well tissue culture plates at a density of $5 \times 10^{5}$ cells per well $(80 \%$ confluence) overnight to allow for adhesion. Prior to infection, the medium was changed to antibiotic- and serum-free DMEM. C. rodentium (DBS100, a gift from the Sherman lab, University of Toronto) was cultured overnight in lysogeny broth (LB) at $37^{\circ} \mathrm{C}$. Cells were treated with the caspase 1 inhibitor AC-YVAD-CMK (25 $\mathrm{MM}$, Enzo Life Sciences, ALX-260-028), or excess $\mathrm{K}^{+}(45 \mathrm{mM})$ to inhibit the inflammasome, for $1 \mathrm{~h}$ preinfection. C. rodentium was added at a multiplicity of infection (MOI) of 10:1 for $2 \mathrm{~h}$ of infection; then ATP $(2.5 \mathrm{mM})$ with or without ROS inhibitors NAC $(20 \mu \mathrm{M})$, DPI $(10 \mu \mathrm{M})$, or apocynin $(4 \mathrm{mM})$ were added for $30 \mathrm{~min}$. The medium was changed to DMEM with gentamicin $(100 \mu \mathrm{g} / \mathrm{ml}$, Fisher Scientific, 15750078) for $1 \mathrm{~h}$ to ensure killing of extracellular bacteria (confirmed by plate growth, not shown; gentamicin does not penetrate the cell membrane so intracellular bacteria remain alive). After incubation with gentamicin, cells were washed thrice with PBS, lysed with Triton X-100 (1\%, 20 min), and bacteria were serially diluted and grown in LB agar plates overnight at $37^{\circ} \mathrm{C}$ for quantification, expressed as $\mathrm{CFU} / \mathrm{ml}$. Results are presented as percent bacterial survival compared to infected well, not treated with inhibitors ('no treatment'). Only colony counting was used for bacterial quantification.

Immunofluorescence was used as a complementary approach for each treatment using green fluorescent protein C. rodentium (GFP-DBS 100, a generous gift from Dr. Bruce Vallance, University of British Columbia). Cells were grown on $13 \mathrm{~mm}$ coverslips, fixed with 4\% PFA (15 min), and blocked in 2\% Goat Serum and $1 \%$ bovine serum albumin (15 min). Actin was stained with Alexa Fluor-594 phalloidin (1:40 dilution, $0.1 \%$ Triton, $0.2 \%$ Goat Serum, and 0.1\% BSA, Fisher Scientific); 4', 6-diamidino-2-phenylindole (DAPI) (1:1000 dilution, $0.1 \%$ Triton, $0.2 \%$ Goat Serum, and $0.1 \%$ BSA) was used for nuclear staining. Slides were analyzed using Zeiss Axio Observer.Z1 microscope with ZEN Imaging software (Carl Zeiss Canada Ltd., Toronto, ON, Canada) and the illustrations were formatted for noise reduction and increased sharpness using Image J. All images were processed identically.

Phagocytosis was determined using the same method as above except with Fluoresbrite carboxylate YG one micron microsphere beads (Polysciences Inc., 18604) instead of bacteria. Beads were used to quantify phagocytosis as they are inert objects that cannot be destroyed by the maturation of the phagosomes. Quantification of intracellular beads was done using Image J and was presented as the mean number of beads per macrophage.

\section{Cell toxicity}

J774A.1 cells were seeded into 6-well dishes at $1 \times 10^{6}$ cells/well (80\% confluence) overnight. Cells were either infected or left uninfected for $2 \mathrm{~h}$, then ATP $(2.5 \mathrm{mM})$ was added for $30 \mathrm{~min}$, and then trypan blue (Life Technologies, 15250061) was added to the medium (only penetrates damaged/dying cells). Damaged cells (stained by trypan blue) were blindly counted per field of view, using 20X magnification from six random locations in each treatment. The percentage was calculated as the number of dead cells out of the total number of cells in each field of view.

\section{Multiplex cytokine assay and IL-1 $\beta$ ELISA}

J774A.1 cells were seeded into 6-well dishes at $1 \times 10^{6}$ cells/well (80\% confluence) overnight. Infection proceeded as above, except gentamicin $(100 \mu \mathrm{g} / \mathrm{mL}$ was left on overnight). Supernatants were collected the following day and analyzed using a multiplex Cytokine kit (Meso Scale Discovery, K15012B), measuring IL-1 $\beta$, IL-6, IL-10, IL-12p70, keratinocyte chemoattractant/human growth-related oncogene (KC/GRO), interferon (IFN)- $\gamma$, and tumor necrosis factor (TNF)- $\alpha$, following the manufacturer's instructions.

Intracellular pro and mature IL-1 $\beta$ were measured from cell lysates, along with secreted IL-1 $\beta$ collected from supernatants, using ELISA (R\&D, DY401). In brief, cells were either inhibited for $1 \mathrm{~h}$ with YVAD $(25 \mu \mathrm{M})$ or $\mathrm{K}^{+}(45 \mathrm{mM})$ or left uninhibited and then infected with C. rodentium for $2 \mathrm{~h}$. This was followed by $30 \mathrm{~min}$ ATP $(2.5 \mu \mathrm{M})$ treatment with or without ROS inhibitors [NAC $(20 \mu \mathrm{M})$, DPI $(10 \mu \mathrm{M})$, or apocynin $(4 \mathrm{mM})]$. Cells were washed with PBS thrice and lysed with M-PER mammalian protein extraction reagent (Fisher Scientific, 78503). Protease inhibitor cocktail (0.08M EDTA, 0.08M phenylmethylsulfonyl fluoride, $0.8 \mathrm{M}$ pepstein) was added and the lysate was centrifuged at $18,800 \mathrm{~g}$ for $10 \mathrm{~min}$ to pellet cell debris. 


\section{Cellular Physiology Cell Physiol Biochem 2017;41:193-204 \\ \begin{tabular}{ll|l} 
and Biochemistry Publisned onIIne: January 18, 2017 & $\begin{array}{l}\text { (c) } 2017 \text { The Author(s). Published by S. Karger AG, Basel } \\
\text { www.karger.com/cpb }\end{array}$ \\
\hline Bording-Jorgensen et al : Inflammasome Enhances Bacterial Clearance by Macrophages
\end{tabular}}

Cell lysate supernatants were then centrifuged using 30k Amicon Ultra-4 centrifugal filters (following the manufacturer's instructions) to separate the mature and pro forms of IL-1 $1 \beta, 17 \mathrm{kDa}$ and $37 \mathrm{kDa}$, respectively.

ROS measurements

ROS was measured using a previously described method [21, 22]. In brief, J774A.1 macrophages were seeded overnight at $5 \times 10^{4}$ (80\% confluence) cells per well in a 96-well plate. DCFDA $(1 \mu \mathrm{M})$ was added for $30 \mathrm{~min}$, then washed with PBS, and fresh DMEM was added for infection. Cells were either left uninhibited or inhibited for $1 \mathrm{~h}$ with YVAD $(25 \mathrm{uM})$ or $\mathrm{K}^{+}$and then infected with C. rodentium for $2 \mathrm{~h}$, followed by 30 min ATP treatment $(2.5 \mu \mathrm{M})$ with or without NAC $(20 \mu \mathrm{M})$, DPI $(10 \mu \mathrm{M})$, or apocynin $(4 \mathrm{mM})$. Fluorescence was measured at $\mathrm{Ex}_{485}$ and $\mathrm{Em}_{535}$. Fold changes in ROS production were normalized to control cells and compared to infected, untreated cell, which were considered as positive controls.

Statistical analysis

Statistical analysis was performed using Prism5 for Windows (Graph Pad, San Diego, CA, USA). MannWhitney two-tailed $t$-test was used for comparison between different treatments. Kruskal-Wallis ANOVA with Dunn's Multiple comparison test were used for phagocytosis determination and cell viability. Bar graphs represent the mean \pm SEM and all comparisons with $\mathrm{P}<0.05$ were considered significant.

\section{Results}

Addition of extracellular ATP enhances bacterial killing by macrophages To determine if inflammasome activation using extracellular ATP would enhance bacterial killing, J774A.1 macrophages were stimulated with exogenous extracellular ATP after being infected with $C$. rodentium. A dose response analysis showed that both $2.5 \mathrm{mM}$ and $5 \mathrm{mM}$ concentrations of extracellular ATP for $30 \mathrm{~min}$ caused a significant reduction in intracellular survival of $C$. rodentium $[(\mathrm{P}<0.05$; Fig. $1 \mathrm{~A} \& \mathrm{~B})]$. A $2.5 \mathrm{mM}$ concentration of extracellular ATP has been shown to be physiologically relevant to the gut setting and to activate the NLRP3 inflammasome and was therefore used in subsequent experiments $[14,23]$. While the inflammasome inhibitors $\mathrm{K}^{+}$and YVAD had no effect on bacterial survival alone, YVAD and $\mathrm{K}^{+}$significantly increased bacterial survival $(\mathrm{P}<0.05$; Fig. $1 \mathrm{C}-\mathrm{E})$ in the presence of ATP as compared to no treatment (NT). In addition, ATP was found to have no effect on phagocytosis as uptake of fluorescent microspheres was unaltered by the various treatments (Fig. 1F\&G). Trypan blue exclusion showed that ATP-induced inflammasome activation did not result in increased cell death (Fig. 1H).

Extracellular ATP induces $I L-1 \beta$ maturation and reduces pro-inflammatory cytokine production

Addition of ATP did not increase secreted total IL-1 $\beta$; however, both YVAD and $\mathrm{K}^{+}$ significantly inhibited IL- $1 \beta$ secretion $(\mathrm{P}<0.05$; Fig. $2 \mathrm{~A})$. The amount of the pro IL- $1 \beta$ was not changed by any of the treatments of infected cells, suggesting that, as expected, 'signal one' is independent of inflammasome manipulation (Fig. 2B). Further supporting a specific effect on inflammasome activation, intracellular mature IL-1 $\beta$ was significantly increased by ATP and inhibited by $\mathrm{K}^{+}$and YVAD $(\mathrm{P}<0.05$; Fig. $2 \mathrm{C})$.

To determine potential effects of ATP activation of the inflammasome, beyond bacterial killing, specifically on the associated immune responses, we used a multiplex cytokine assay. TNF- $\alpha$ and IL- 6 were decreased $(\mathrm{P}<0.05$; Fig. 3A\&B), whereas IL-12p70 was significantly increased after exposure of infected macrophages to ATP $(\mathrm{P}<0.05$; Fig. $3 \mathrm{C})$. There was no effect of ATP on KC/GRO, IFN- $\gamma$, or secreted IL-1 $\beta$ (data not shown). IL-10 did not show a significant change but did indicate an increasing trend with the addition of ATP (Fig. 3D). These findings not only support activation of the inflammasome by ATP but also demonstrate effects on other cytokines, specifically a reduction in the pro-inflammatory cytokines IL-6 and $\mathrm{TNF} \alpha$, related to bacterial clearance. 


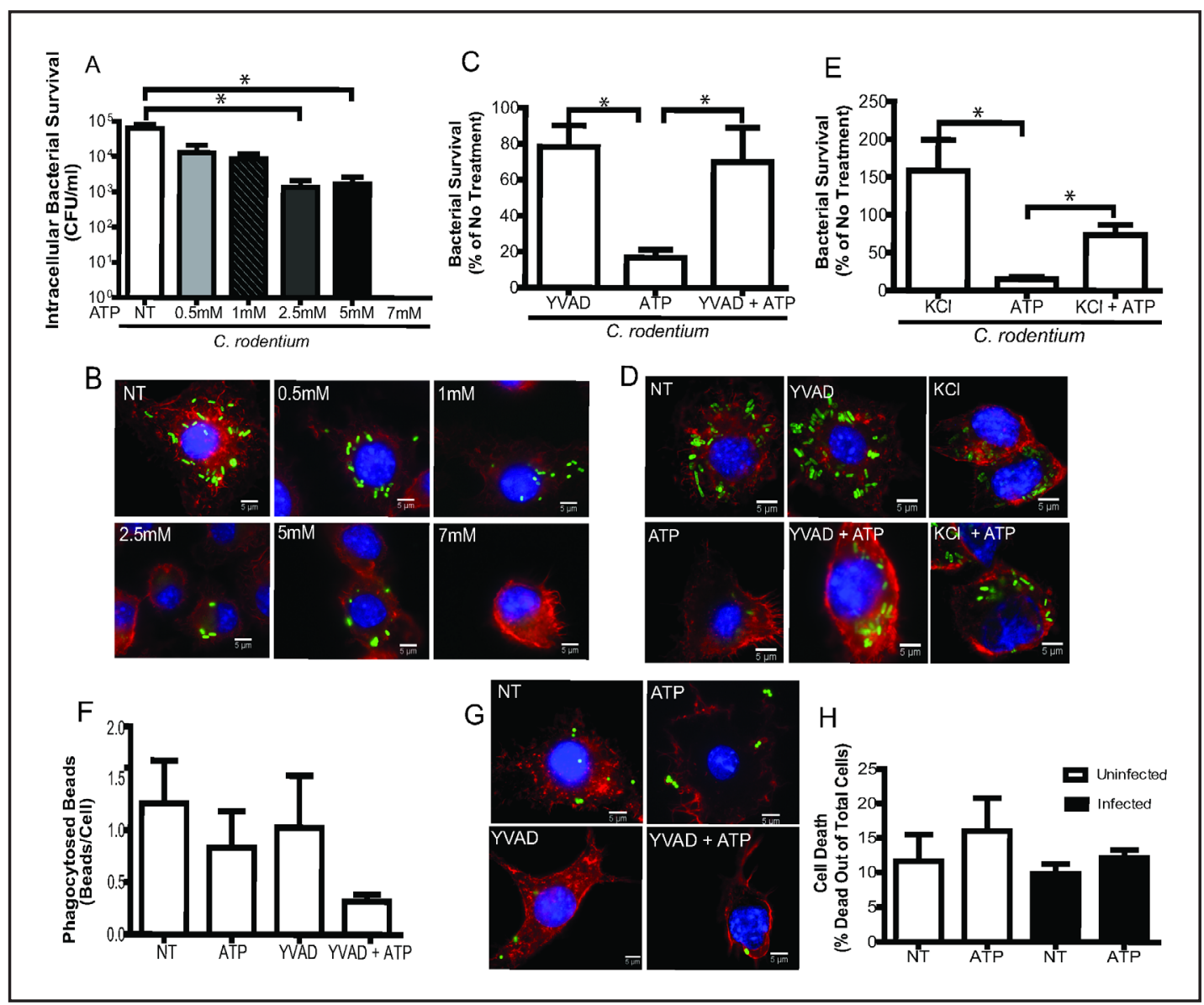

Fig. 1. ATP induces and YVAD and $\mathrm{K}^{+}$inhibit $C$. rodentium killing by macrophages with no effect on phagocytosis or cell death. ATP dose analysis was generated to determine optimal concentrations for bacterial killing $(\mathrm{P}<0.05$; $\mathrm{A}$ and $\mathrm{B})$. Macrophages were inhibited with YVAD $(25 \mu \mathrm{M})$ or $\mathrm{K}^{+}(45 \mathrm{mM})$ for $1 \mathrm{hr}$, infected with $C$. rodentium for $2 \mathrm{hr}$, and ATP $(2.5 \mathrm{mM})$ was added for $30 \mathrm{~min}$. Cells were then rinsed and gentamicin introduced to kill extracellular bacteria. Intracellular bacteria were quantified by plating overnight. In addition to confirming enhanced killing after addition of ATP, YVAD significantly inhibited (C), while K+ inhibition partially inhibited bacterial killing (E), supporting specific effects of ATP on the inflammasome. (D) Representative immunofluorescence images using DAPI (blue) for the nucleus, Phalloidin (red) for actin, and GFP-labelled (green) C. rodentium. Data in panels $\mathrm{C}$ and $\mathrm{E}$ are shown as a percent survival of $C$. rodentium as compared to infected, untreated cells (NT). Only CFU counting, and not the micrographs, was used to calculate the number of surviving bacteria. Statistical analysis was done using one-way ANOVA with Tukey's multiple comparison test. $\mathrm{N}=9-12$. ${ }^{*} \mathrm{P}<0.05$. (F) Macrophages were inhibited with YVAD $(25 \mu \mathrm{M})$; fluorescent beads and $2.5 \mathrm{mM}$ ATP were added. Numbers of intracellular beads were counted and presented as beads per macrophage. $N=4$. (G) Representative immunofluorescence images using DAPI (blue) for the nucleus, Phalloidin (red) for actin, and microsphere beads (green). (H) Macrophages were inhibited with YVAD (25 $\mu \mathrm{M}$ ) or activated with $2.5 \mathrm{mM}$ ATP. Cells were either infected (solid bars) or left uninfected (clear bars) for $2.5 \mathrm{hr}$; trypan blue was added and viability calculated by counting the proportion of dead cells per field of view. Statistical Analysis was done using one-way ANOVA with Tukey's multiple comparison test. N=3.

Bactericidal effects of ATP are associated with an increase in ROS

To assess whether ROS is associated with, and possibly mediates the inflammasomeinduced bacterial clearance, we used 2, 7-dichlorofluorescein diacetate (DCFDA) to measure ROS production. ROS production was significantly increased with the addition of ATP and 
this was inhibited by the inflammasome inhibitors YVAD and $\mathrm{K}^{+}(\mathrm{P}<0.05$; Fig. 4A\&B), as well as the ROS inhibitors NAC, apocynin, and DPI (used as controls; P<0.05; Fig. 4CE), suggesting that ROS is associated with inflammasome-induced bacterial killing; however, it was not clear whether this was the cause (upstream) or result (downstream) of inflammasome activation.

To address the causal relationship between ROS, the inflammasome, and bacterial killing by macrophages we used ROS inhibitors and assessed their impact on IL-1 $\beta$ production and bacterial survival with inflammasome activation. Inhibition of ROS did not reduce IL-1 $\beta$ release, indicating that inflammasome activation is not dependent on ROS (data not shown); however, NAC and apocynin significantly increased bacterial survival in the presence of ATP $(\mathrm{P}<0.05$; Fig. 5A\&B; the effect of DPI did not reach significance; Fig. 5C). This suggests that ATP-induced inflammasome activation and bacterial killing by macrophages are at least partially mediated by and dependent on ROS activity.

\section{Discussion}

The complex relationship between bacteria and the immune response they induce, especially in the gut, is thought to contribute to immune-mediated conditions, such as IBD [24]. NOD2 is an innate immune cytosolic microbial sensor, which detects the muramyl dipeptide component of peptidoglycan; a frameshift mutation causing a NOD2 deficiency has been linked to Crohn disease susceptibility $[25,26]$. The NLRP3 inflammasome is also an innate sensor of bacteria, and closely related to NOD2, that appears to have conflicting roles in different inflammatory conditions - detrimental in extraintestinal conditions and protective in IBD $[27,28]$. We hypothesized that this discrepancy could be explained by the role of

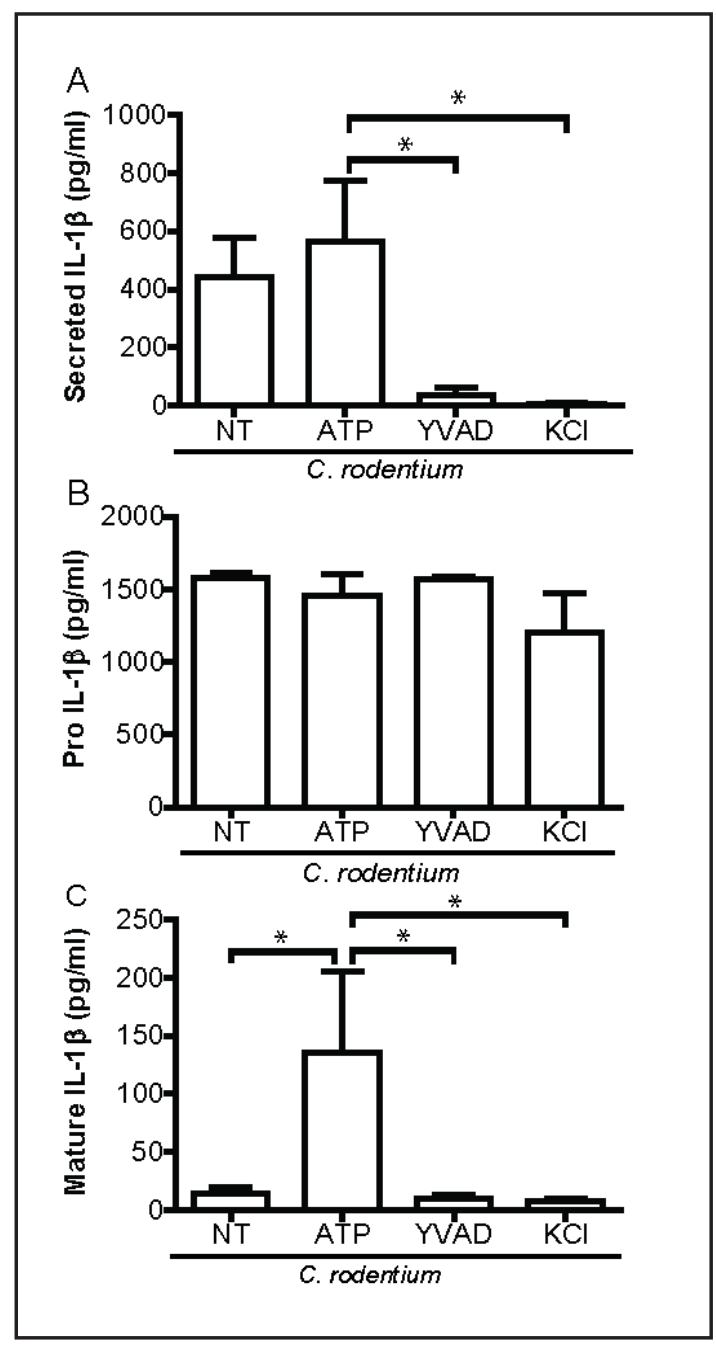

Fig. 2. ATP increases intracellular mature IL-1 $1 \beta$ but not pro IL-1 $\beta$. Macrophages were inhibited with YVAD $(25 \mu \mathrm{M})$ or $\mathrm{K}^{+}(45 \mathrm{mM})$, infected, and $2.5 \mathrm{mM}$ ATP added. (A) Secreted IL-1 $\beta$, measured using ELISA, was not increased with the addition of ATP but was significantly reduced with the addition of $\mathrm{K}^{+}$or YVAD. Cells were lysed using mammalian lysis buffer; pro (B) and mature (C) IL- $1 \beta$ were separated using $30 \mathrm{kDa}$ centrifugal filters and measured using ELISA. ATP significantly increased intracellular mature IL$1 \beta$ and $\mathrm{K}^{+}$inhibited this increase. Statistical analysis was done using one-way ANOVA with Tukey's multiple comparison test. ${ }^{*} \mathrm{P}<0.05$. $\mathrm{N}=3$ for pro IL- $1 \beta ; \mathrm{n}=8$ for mature IL-1 $1 \beta$.

the NLRP3 inflammasome in bacterial killing by macrophages in the microbe-rich gut (in contrast to relatively sterile extraintestinal sites).

Using ATP to activate the NLRP3 inflammasome, we demonstrated an increased capacity of inflammasome-activated macrophages to kill intracellular bacteria, which is retarded when the inflammasome is suppressed using inhibitors, ROS scavengers, and ROS inhibitors, supporting specificity of our model. Interestingly, we found that more effective bacterial killing through inflammasome activation also reduced pro-inflammatory responses, with 
Fig. 3. Pro-inflammatory cytokines are reduced by addition of ATP to infected macrophages. Macrophages were inhibited with YVAD $(25 \mu \mathrm{M})$, infected, and $2.5 \mathrm{mM}$ ATP was added. Cells were then washed, and gentamicin introduced overnight to kill extracellular bacteria. Supernatants were collected and a multiplex cytokine array was conducted; data are shown for (A) TNF $\alpha$, (B) IL-6, (C), IL-12, and (D) IL-10. ATP caused a reduction in pro-inflammatory mediators IL-6 and $\mathrm{TNF} \alpha$ while showing an increase in IL-12 and a trend for the anti-inflammatory mediator IL-10. Statistical analysis was done using one-way ANOVA with Tukey's multiple comparison test. $\mathrm{N}=5$; ${ }^{*} \mathrm{P}<0.05$.

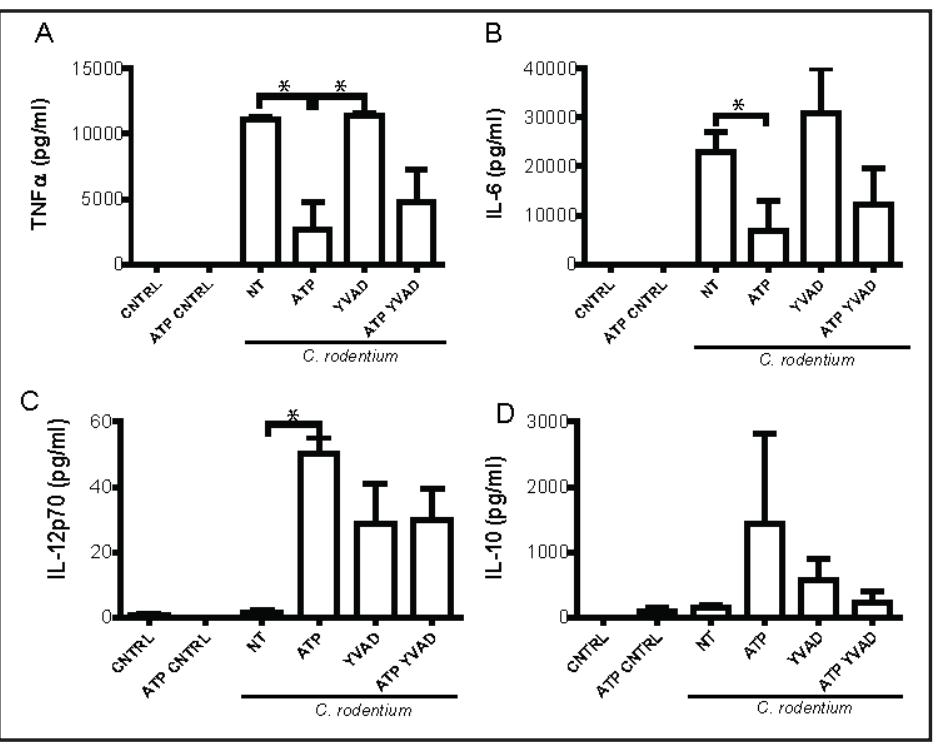
one-way ANOVA with Tukey's multiplecomparison test. N=5; $* 2<0.05$.

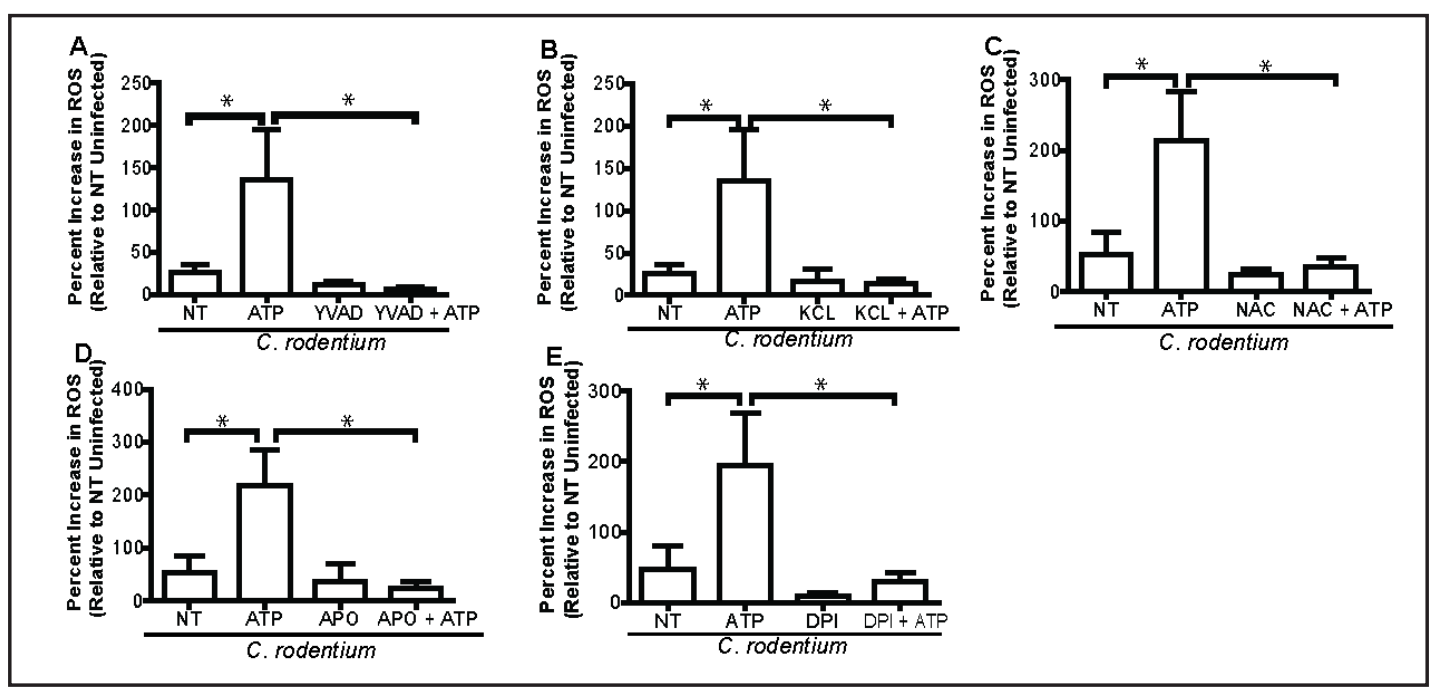

Fig. 4. ATP-induced inflammasome activation increases intracellular reactive oxygen species (ROS) generation. DCFDA was added to macrophages, which were then inhibited with YVAD $(25 \mu \mathrm{M}, \mathrm{A})$ or $\mathrm{K}^{+}(45 \mathrm{mM}, \mathrm{B})$, infected, and treated with $2.5 \mathrm{mM}$ ATP with and without ROS inhibitors N-acetyl cysteine (NAC) (20 $\mu \mathrm{M}, \mathrm{C})$, apocynin (APO) (4 mM, D), or diphenyleneiodonium (DPI) (10 $\mu \mathrm{M}, \mathrm{E})$ followed by ROS measurement. Changes in ROS production were normalized to uninfected, untreated cells. Statistical analysis was done using one-way ANOVA with Tukey's multiple comparison test. $* \mathrm{P}<0.05$. N=3.

reductions in TNF $\alpha$ and IL-6; this may be relevant to IBD, where the inflammasome appears to be protective, as improved bacterial clearance by inflammasome-activated macrophages may reduce the uncontrolled immune activation, observed when bacteria are not effectively controlled. In contrast, in other chronic immune-mediated conditions, such as familial Mediterranean fever, gout, and rheumatoid arthritis, inflammasomes are recognized as major contributors to pathogenesis, possibly since bacteria are not central to these conditions and failure of bacterial killing will not lead to more inflammation but secretion of excess IL-1 $\beta$ by the activated inflammasome might [5]. The common theme between these extraintestinal conditions is the overabundance of IL-1 $\beta$ and, in fact, anti-IL-1 $\beta$ drugs are being considered as potential treatments for these conditions [5]. However in Crohn disease an opposite (and 


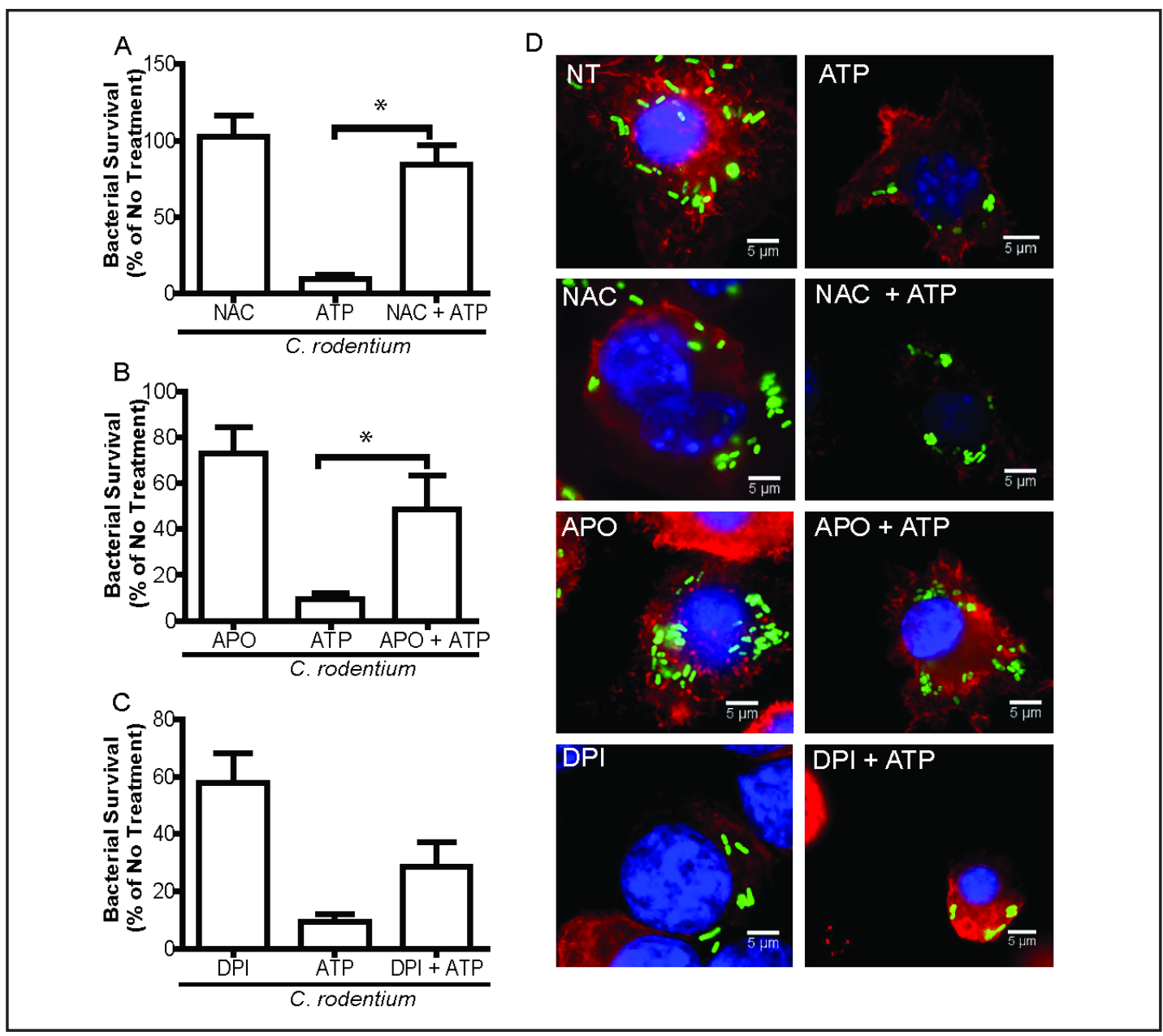

Fig. 5. Inhibition of ATP-driven intracellular reactive oxygen species (ROS) generation increases intracellular $C$. rodentium survival. Macrophages were infected for $2 \mathrm{hr}$, and then inhibited with $\mathrm{N}$-acetyl cysteine $(20 \mu \mathrm{M})$, diphenyleneiodonium $(10 \mu \mathrm{M})$, or apocynin $(4 \mathrm{mM})$ with or without $2.5 \mathrm{mM}$ ATP added. Cells were then washed and gentamicin introduced to kill extracellular bacteria. Intracellular bacteria were quantified by plating overnight and serial dilutions. (A) N-acetyl cysteine (NAC) and (B) apocynin (APO) significantly inhibited bacterial killing while (C) diphenyleneiodonium (DPI) did not. (D) Representative immunofluorescence images using DAPI (blue) for the nucleus, Phalloidin (red) for actin, and GFP-labelled (green) C. rodentium. Data are shown as a percent survival of $C$. rodentium as compared to infected, no treatment (NT). Statistical analysis was done using one-way ANOVA with Tukey's multiple comparison test. N= 8-10. $* \mathrm{P}<0.05$.

protective) role for the inflammasome is suggested as reduced production of IL-1 $\beta$ and decreased expression of the NLRP3 gene have been observed, which, given our findings, may reflect a deficiency in killing bacteria, leading to inappropriate immune activation [11].

Bacterial-induced inflammasome activation requires live bacteria, as ATP has been shown to protect mice against $E$. coli and $S$. aureus infections through neutrophil recruitment and inflammasome activation [12, 29]. We showed that, at physiologic concentrations, ATP reduced the survival of intracellular $C$. rodentium with inhibition by YVAD and partial inhibition by $\mathrm{K}^{+}$. This suggests that ATP-induced inflammasome activation plays an important role in intracellular bacterial killing, supporting the findings of Xiang et al. with E. coli and $S$. aureus [12].

In order to differentiate between uptake by macrophages (phagocytosis), replication within macrophages, and bacterial killing by macrophages, we incubated macrophages 
with inert fluorescent beads and assessed effects of inflammasome manipulation. Neither inflammasome activation nor inhibition affected the rate of bead phagocytosis, suggesting that the inflammasome is not directly involved in phagocytosis but rather in elimination of bacteria (or inhibiting bacterial replication), likely through the phagosome maturation process. Inflammasome activation can lead to pyroptosis, a form of programmed cell death, which could result in a loss of membrane integrity and gentamicin leakage, causing microbial cell death. Macrophage cell death was not increased by either ATP addition or $C$. rodentium infection, suggesting that the duration of infection and ATP exposure used were not causing late stages of cell death.

Intracellular pro-IL-1 $\beta$ was not different between any of the inflammasome manipulation treatments, which is expected as this requires 'signal one' that is provided by $C$. rodentium. As anticipated, intracellular mature IL-1 $\beta$ was significantly increased by ATP and inhibited by $\mathrm{K}^{+}$and YVAD. Another interesting observation was the change in cytokine profiles with the addition of ATP. This may suggest a switch from a $\mathrm{Th}_{1} / \mathrm{Th}_{17}$ proinflammatory response to a more regulatory IL-10-mediated response due to activation of NLRP3 by ATP. IL- 6 is required for differentiation of naïve T cells into $\mathrm{Th}_{17}$ cells and TNF- $\alpha$ is a major product of $\mathrm{Th}_{1}$ cells; therefore, this observation is important in understanding the role of macrophages and bacterial killing during chronic infections. [30] As Crohn disease is known to be a $\mathrm{Th}_{17^{-}}$ mediated inflammatory condition, the dysregulation (or dysfunction) of the inflammasome could lead to increased concentration of IL- 6 and TNF- $\alpha$, resulting in infiltration of $\mathrm{Th}_{17}$ cells into the lamina propria and more inflammation. This could be the consequence of impaired bacterial killing, as ATP appeared to reduce pro-inflammatory cytokines in our study [31].

There is some debate in the literature whether ROS activates the inflammasome or the reverse [32]. Our findings suggest that ATP activates the inflammasome, which then increases ROS production, as shown by ROS reduction with inflammasome inhibitors without a change in IL-1 $\beta$ production with ROS inhibitors. NAC is a ROS scavenger that is not specific to any organelle or complex and therefore does not contribute to our understanding of the mechanism for inflammasome-activated ROS production. DPI, a NADPH oxidase inhibitor, did not show any bactericidal inhibition, suggesting involvement of a different ROS producer outside the phagolysosome. Apocynin, another inhibitor of the NADPH oxidase complex and hydrogen peroxide scavenger, showed an increase in bacterial survival, suggesting that the ROS species responsible for microbial death is hydrogen peroxide and that this is not mediated by the NADPH oxidase complex [33]. In contrast to our findings, alveolar macrophages have been shown to have ROS-induced inflammasome activation in an LPS-ATP model [34]. Another study showed that inhibition of ROS results in decreased LPS and ATP-induced inflammasome activation in J774A.1 cells [3]. However, these studies illustrate the relationship between ROS production and the inflammasome either in a sterile inflammatory state or where there are no live bacteria present. In addition, patients with chronic granulomatous disease, lacking NADPH oxidase activity, are still capable of secreting normal levels of IL-1 $\beta$ [35]. This is in accordance with our findings that inflammasome activation was not affected when the three ROS inhibitors (NAC, DPI, or Apocynin) were added along with ATP to the macrophages during the infection. Nevertheless, it is possible that both ROS and the inflammasome are affected by LPS, or other bacterial factors, through NOX activation, for example. While our study did not directly address this possibility, we did show that at least in part, inhibiting the inflammasome reduces ROS and that ROS is required to eliminate bacteria. Future studies will focus on delineating the mechanism of inflammasomeinduced ROS production as there is some evidence suggesting that mitochondria, which can be affected by P2X ${ }_{7}$ activation, interact with the NLRP3 inflammasome [36, 37].

In Summary, our in vitro study reinforces the importance of the inflammasome in regulating and clearing enteric pathogens and possibly explains the unique role of inflammasomes in the gut, in the context of IBD, and why this is different from other settings. Bacterial killing by the inflammasome is mediated by ROS production, as shown by use of ROS inhibitors. We also show that ATP (through inflammasome activation) changes the 
Fig 6. Suggested model of ATP-induced inflammasome activation and ROS production. Black arrows: Bacterial components from $C$. rodentium act as 'signal 1', through Toll-like receptor (TLR) 4, which leads to the activation of nuclear factor- $\mathrm{KB}\left(\mathrm{NF}_{\mathrm{K}} \mathrm{B}\right)$ and phagocytosis. $\mathrm{NF}_{\mathrm{k}} \mathrm{B}$ signalling induces the transcription and translation of pro-IL$1 \beta$ and NLRP3 proteins. Green arrows: Extracellular ATP then provides 'signal 2' through the purinergic receptor $\mathrm{P} 2 \mathrm{X}_{7}$, causing pannexin 1 activation and $\mathrm{K}^{+}$efflux, leading to inflammasome activation. Activation of the inflammasome causes autocleavage of

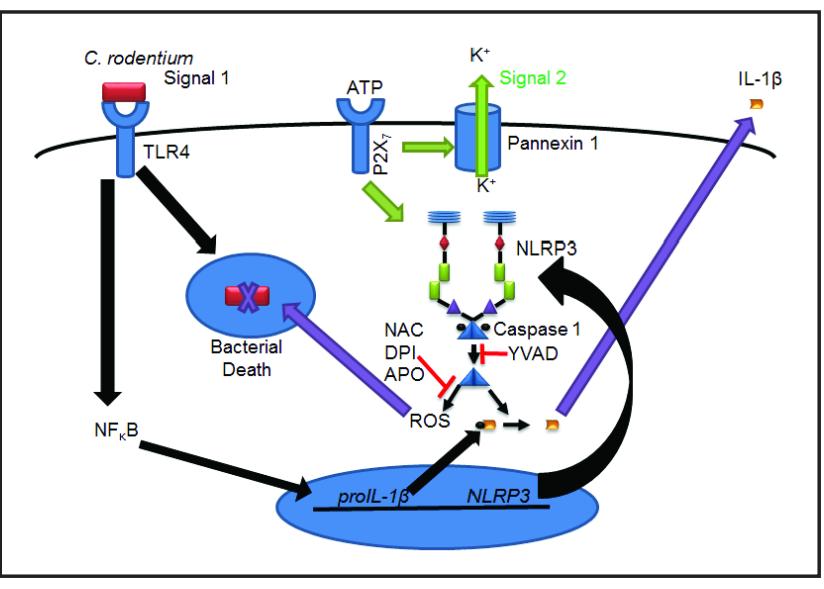
caspase-1 (inhibited by YVAD), which can then cleave pro IL-1 $\beta$ into its mature form that is secreted from the cell. Purple arrows: Inflammasome activation also induces ROS production that can eliminate the phagocytosed bacterium and prevent inappropriate proinflammatory responses.

immune milieu in a way that could reduce the vicious inflammatory cycle in the gut. With these findings, we propose a model (Fig. 6) for ATP-induced inflammasome activation and ROS production during C. rodentium phagocytosis in J774A.1 macrophages. Understanding the mechanisms used by macrophages to kill bacteria, and therefore affect inflammatory responses, could lead to valuable insight into chronic inflammatory conditions, such as IBD, and potential new treatment approaches for these chronic conditions. Appropriate activation of the inflammasome may, therefore, improve control of intestinal bacteria and reduce the exaggerated compensatory immune response seen in IBD.

\section{Acknowledgements}

We would like to acknowledge Yuefei Lou, Richard Chan, and Rosanne Govaarts for their technical assistance, and Drs. Philip Sherman and Bruce Vallance for providing bacterial strains of DBS 100, and GFP-DBS 100, respectively.

\section{Funding}

This work was supported by grants awarded by Alberta Innovates-Health Solutions (AIHS) and the Crohn's and Colitis Foundation of America (CCFA) to EW. Infrastructure in EW's laboratory is funded by the Centre of Excellence for Gastrointestinal Inflammation and Immunity Research (CEGIIR) at the University of Alberta. MBJ is supported by a Graduate studentship from the University of Alberta, Department of Physiology. MA is the recipient of Postdoctoral Fellowships from Canadian Institutes of Health Research/Canadian Association of Gastroenterology (CIHR/CAG) and AIHS. GD was supported by a Summer Studentship from Women and Children's Health Research Institute (WCHRI).

\section{Disclosure Statement}

The authors have no conflicts of interest relevant to this manuscript. 


\section{Cellular Physiology Cell Physiol Biochem 2017;41:193-204

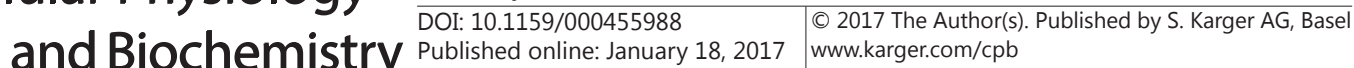

\section{References}

1 Lamkanfi M, Dixit VM: Mechanisms and functions of inflammasomes. Cell 2014;157:1013-1022.

2 Sutterwala FS, Haasken S, Cassel SL: Mechanism of NLRP3 inflammasome activation. Ann N Y Acad Sci 2014;1319:82-95.

-3 Liao PC, Chao LK, Chou JC, Dong WC, Lin CN, Lin CY, Chen A, Ka SM, Ho CL, Hua KF: Lipopolysaccharide/ adenosine triphosphate-mediated signal transduction in the regulation of NLRP3 protein expression and caspase-1-mediated interleukin-1beta secretion. Inflamm Res 2013;62:89-96.

-4 Latz E, Xiao TS, Stutz A: Activation and regulation of the inflammasomes. Nat Rev Immunol 2013;13:397411.

-5 Dinarello CA, Simon A, van der Meer JW: Treating inflammation by blocking interleukin-1 in a broad spectrum of diseases. Nat Rev Drug Discov 2012;11:633-652.

-6 De Nardo D, De Nardo CM, Latz E: New insights into mechanisms controlling the NLRP3 inflammasome and its role in lung disease. Am J Pathol 2014;184:42-54.

7 Im H, Ammit AJ: The NLRP3 inflammasome: role in airway inflammation. Clin Exp Allergy 2014;44:160172.

8 Simpson JL, Phipps S, Baines KJ, Oreo KM, Gunawardhana L, Gibson PG: Elevated expression of the NLRP3 inflammasome in neutrophilic asthma. Eur Respir J 2014;43:1067-1076.

-9 Vande Walle L, Van Opdenbosch N, Jacques P, Fossoul A, Verheugen E, Vogel P, Beyaert R, Elewaut D, Kanneganti TD, van Loo G, Lamkanfi M: Negative regulation of the NLRP3 inflammasome by A20 protects against arthritis. Nature 2014;512:69-73.

10 Gattorno M, Martini A: Review: Beyond the NLRP3 Inflammasome: Autoinflammatory Diseases Reach Adolescence. Arthritis Rheum 2013;65:1137-1147.

11 Villani AC, Lemire M, Fortin G, Louis E, Silverberg MS, Collette C, Baba N, Libioulle C, Belaiche J, Bitton A, Gaudet D, Cohen A, Langelier D, Fortin PR, Wither JE, Sarfati M, Rutgeerts P, Rioux JD, Vermeire S, Hudson TJ, Franchimont D: Common variants in the NLRP3 region contribute to Crohn's disease susceptibility. Nat Genet 2009;41:71-76.

12 Xiang Y, Wang X, Yan C, Gao Q Li SA, Liu J, Zhou K, Guo X, Lee W, Zhang Y: Adenosine-5'-triphosphate (ATP) protects mice against bacterial infection by activation of the NLRP3 inflammasome. PLoS One 2013;8:e63759.

13 Gicquel T, Victoni T, Fautrel A, Robert S, Gleonnec F, Guezingar M, Couillin I, Catros V, Boichot E, Lagente V: Involvement of purinergic receptors and NLRP3-inflammasome pathway in the ATP-induced cytokine release from macrophages. Clin Exp Pharmacol Physiol 2014;41:279-286.

-14 Pelegrin P, Barroso-Gutierrez C, Surprenant A: P2X7 receptor differentially couples to distinct release pathways for IL-1beta in mouse macrophage. J Immunol 2008;180:7147-7157.

15 Hua KF, Chou JC, Ka SM, Tasi YL, Chen A, Wu SH, Chiu HW, Wong WT, Wang YF, Tsai CL, Ho CL, Lin CH: Cyclooxygenase-2 Regulates NLRP3 Inflammasome-Derived IL-1beta Production. J Cell Physiol 2015;230:863-874.

16 Tschopp J, Schroder K: NLRP3 inflammasome activation: The convergence of multiple signalling pathways on ROS production? Nat Rev Immunol 2010;10:210-215.

17 Spooner R, Yilmaz 0: The role of reactive-oxygen-species in microbial persistence and inflammation. Int J Mol Sci 2011;12:334-352.

18 Petrilli V, Papin S, Dostert C, Mayor A, Martinon F, Tschopp J: Activation of the NALP3 inflammasome is triggered by low intracellular potassium concentration. Cell Death Differ 2007;14:1583-1589.

19 Csoka B, Nemeth ZH, Toro G, Idzko M, Zech A, Koscso B, Spolarics Z, Antonioli L, Cseri K, Erdelyi K, Pacher P, Hasko G: Extracellular ATP protects against sepsis through macrophage P2X7 purinergic receptors by enhancing intracellular bacterial killing. FASEB J 2015;29:3626-3637.

20 Alipour M, Lou Y, Zimmerman D, Bording-Jorgensen MW, Sergi C, Liu JJ, Wine E: A balanced IL-1beta activity is required for host response to Citrobacter rodentium infection. PLoS One 2013;8:e80656.

21 Wu D, Yotnda P: Production and detection of reactive oxygen species (ROS) in cancers. J Vis Exp 2011;57.

22 Van Acker H, Gielis J, Acke M, Cools F, Cos P, Coenye T: The Role of Reactive Oxygen Species in AntibioticInduced Cell Death in Burkholderia cepacia Complex Bacteria. PLoS One 2016;11:e0159837.

23 Burnstock G: Purinergic signalling in the gastrointestinal tract and related organs in health and disease. Purinergic Signal 2014;10:3-50. 


\section{Cellular Physiology Cell Physiol Biochem 2017;41:193-204

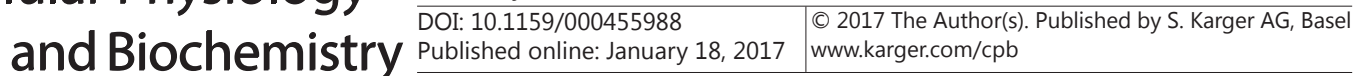

24 Abraham C, Medzhitov R: Interactions between the host innate immune system and microbes in inflammatory bowel disease. Gastroenterology 2011;140:1729-1737.

25 Miner-Williams WM, Moughan PJ: Intestinal barrier dysfunction: implications for chronic inflammatory conditions of the bowel. Nutr Res Rev 2016;29:40-59.

-26 Ogura Y, Bonen DK, Inohara N, Nicolae DL, Chen FF, Ramos R, Britton H, Moran T, Karaliuskas R, Duerr RH, Achkar JP, Brant SR, Bayless TM, Kirschner BS, Hanauer SB, Nunez G, Cho JH: A frameshift mutation in NOD2 associated with susceptibility to Crohn's disease. Nature 2001;411:603-606.

-27 Hirota SA, Ng J, Lueng A, Khajah M, Parhar K, Li Y, Lam V, Potentier MS, Ng K, Bawa M, McCafferty DM, Rioux KP, Ghosh S, Xavier RJ, Colgan SP, Tschopp J, Muruve D, MacDonald JA, Beck PL: NLRP3 inflammasome plays a key role in the regulation of intestinal homeostasis. Inflamm Bowel Dis 2011;17:1359-1372.

28 Song-Zhao GX, Srinivasan N, Pott J, Baban D, Frankel G, Maloy KJ: Nlrp3 activation in the intestinal epithelium protects against a mucosal pathogen. Mucosal Immunol 2014;7:763-774.

29 Sander LE, Davis MJ, Boekschoten MV, Amsen D, Dascher CC, Ryffel B, Swanson JA, Muller M, Blander JM: Detection of prokaryotic mRNA signifies microbial viability and promotes immunity. Nature 2011;474:385-389.

- 30 Zambrano-Zaragoza JF, Romo-Martinez EJ, Duran-Avelar Mde J, Garcia-Magallanes N, Vibanco-Perez N: Th17 cells in autoimmune and infectious diseases. Int J Inflam 2014;2014:651503.

-31 Troncone E, Marafini I, Pallone F, Monteleone G: Th17 cytokines in inflammatory bowel diseases: discerning the good from the bad. Int Rev Immunol 2013;32:526-533.

-32 Abais JM, Xia M, Zhang Y, Boini KM, Li PL: Redox Regulation of NLRP3 Inflammasomes: ROS as Trigger or Effector? Antioxid Redox Signal 2014;22:1111-1129.

-33 Petronio MS, Zeraik ML, Fonseca LM, Ximenes VF: Apocynin: chemical and biophysical properties of a NADPH oxidase inhibitor. Molecules 2013;18:2821-2839.

-34 Cruz CM, Rinna A, Forman HJ, Ventura AL, Persechini PM, Ojcius DM: ATP activates a reactive oxygen species-dependent oxidative stress response and secretion of proinflammatory cytokines in macrophages. J Biol Chem 2007;282:2871-2879.

-35 van Bruggen R, Koker MY, Jansen M, van Houdt M, Roos D, Kuijpers TW, van den Berg TK: Human NLRP3 inflammasome activation is Nox1-4 independent. Blood 2010;115:5398-5400.

-36 Saitoh T, Akira S: Regulation of inflammasomes by autophagy. J Allergy Clin Immunol 2016;138:28-36.

37 Seeland S, Kettiger H, Murphy M, Treiber A, Giller J, Kiss A, Sube R, Krahenbuhl S, Hafner M, Huwyler J: ATP-induced cellular stress and mitochondrial toxicity in cells expressing purinergic P2X7 receptor. Pharmacol Res Perspect 2015;3:e00123. 